\title{
Defining conditions for biofilm inhibition and eradication assays for Gram-positive clinical reference strains
}

\author{
Cristina D. Cruz, Shreya Shah and Päivi Tammela* (D)
}

\begin{abstract}
Background: Biofilms are formed by a complex bacterial community encapsulated by a polymeric matrix, with strong adherent properties and persistent phenotype. Biofilms are considered one of the most challenging areas of modern medicine. Existing antibiotics have been developed against free-floating bacterial cells, and thus, many treatments of biofilm-related infection fail. In this study, we compared the effects of different media on biofilm growth of clinical reference strains of Staphylococci and Enterococci, including multi-drug resistant representatives. Further, we optimized the resazurin-based assay for determining the minimal biofilm inhibitory concentration (MBIC) of standard antibiotics, and evaluated its use for the determination of minimal biofilm eradication concentration (MBEC).

Results: We showed that tryptic soy broth supplemented with $1 \%$ glucose was an optimal media for maximum biofilm growth of all strains tested, with an extended incubation time for Enterococci. A range of parameters were tested for the resazurin assay, including concentration, temperature and time of incubation. Using quality parameters to analyze the assay's performance, the conditions for the resazurin assay were set as follows: $4 \mu \mathrm{g} / \mathrm{mL}$ and $8 \mu \mathrm{g} / \mathrm{mL}$, with incubation at $25^{\circ} \mathrm{C}$ for 20 min and $40 \mathrm{~min}$ for Staphylococci and Enterococci, respectively.

Conclusions: In summary, we defined conditions for optimal biofilm growth and for standardized resazurin assay for MBIC determination against six Gram-positive clinical reference strains. We also observed that MBEC determination by the resazurin-based assay is limited due to the poor detection limit of the assay. Complementary cell counting data is needed for precise determination of MBEC.
\end{abstract}

Keywords: Biofilm, Media, Glucose, Gram-positive bacteria, Crystal violet, Resazurin, Ciprofloxacin, Linezolid, MBIC, MBEC

\section{Background}

Biofilms can be described as a structured community of bacterial cells enclosed in a polymeric matrix and adherent to an abiotic or biotic surface. Bacteria account for $5-35 \%$ of biofilm volume. The remaining volume is the extracellular matrix, which is an enclosed, hydrated polyanionic complex of exopolysaccharide (EPS) [1]. In contrast to planktonic bacteria, biofilms provide a survival advantage to the microbial community, showing a nearly 1000-fold increase in antimicrobial tolerance [2].

* Correspondence: paivi.tammela@helsinki.fi

Drug Research Program, Division of Pharmaceutical Biosciences, Faculty of Pharmacy, Fl-00014 University of Helsinki, P.O. Box 56, Helsinki, Finland
In recent years, there has been an increase in the number of patients in health care receiving implanted biomaterials, which are notably prone to biofilm colonization [3-5]. Additionally, biofilms play a role in non-device-associated chronic bacterial infections $[1,6]$. Treatment of these infections is not always successful due to bacterial tolerance to conventional antimicrobial agents, thus frequently leading to the surgical removal of the implanted device, involving risks and complications. In this context, biofilm-related infections caused by Gram-positive cocci are well established. For example, Staphylococci is one of the leading causative bacteria of catheters and prosthetic related-infections [4], followed by Enterococci $[6,7]$.

(c) The Author(s). 2018 Open Access This article is distributed under the terms of the Creative Commons Attribution 4.0 International License (http://creativecommons.org/licenses/by/4.0/), which permits unrestricted use, distribution, and 
In general, for routine quantification of bacterial biofilms, total biomass measurements are used based on crystal violet staining, which stains both living and dead cells. Another method commonly used is based on resazurin, a blue non-fluorescent redox dye that is reduced by cellular metabolic activity to highly fluorescent, pink resorufin $[8,9]$. Developments in the field of new antimicrobial agents do not take into account the characteristics of bacteria as biofilms [10], thus the ongoing need for effective biofilm treatment requires standardized screening methods for the reference laboratory. Currently, there is no gold standard method for assessing new anti-biofilm drugs.

Therefore, simple and standardized guidelines for optimal in vitro biofilm production and anti-biofilm susceptibility assays for Gram-positive laboratory reference strains are needed. To our knowledge, this is the first report in which the MBIC and MBEC assay set-ups for clinical reference strains of Staphylococci and Enterococci are systematically assessed and optimized by using the following assay quality parameters, commonly used in high-throughput screening: $Z$ prime (Z'), signal to background (S/B) and signal window (SW). SW and $\mathrm{Z}^{\prime}$ are calculations that measure the fold response between maximum and minimum control signals and the precision of this response (variability). $\mathrm{Z}^{\prime}$ is a representation of SW using a score ranging from 0 to 1 and it is more reliable on assessing assay's acceptability in comparison to $\mathrm{SW} . \mathrm{S} / \mathrm{B}$ is calculated taking into account the averages of minimum and maximum signals only. Acceptable values for the three parameters are: $\mathrm{S} / \mathrm{B}$ and $\mathrm{SW}>2$-fold and for Z'> 0.5 [11].

In particular, this study aimed to 1) evaluate the effects of different media on biofilm production, 2) establish optimal resazurin assay conditions and 3) assess the minimal biofilm inhibitory and eradication concentrations (MBIC and MBEC, respectively) for ciprofloxacin and linezolid against the clinical reference strains using the optimized methodology.

\section{Methods}

\section{Bacterial strains}

Six bacterial strains (Table 1) were purchased from Microbiologics Inc. (St. Cloud, MN, USA), and reconstituted as per the manufacturer's instructions. Bacterial stocks were prepared in cation-adjusted Mueller Hinton broth (MHB, Becton Dickinson, Franklin Lakes, NJ, USA) and stored at $-80{ }^{\circ} \mathrm{C}$. Fresh cultures were initiated on Mueller Hinton agar (MHA) plates on a monthly basis. Overnight cultures were prepared before the assay by subculturing bacterial strains on fresh MHA plates and incubated at $37{ }^{\circ} \mathrm{C}$ for $16-20 \mathrm{~h}$

\section{Biofilm production}

A single colony was taken from the MHA overnight bacterial culture, inoculated into $0.85 \%$ saline solution and vortexed to ensure that the bacterial suspension was homogeneous. Bacterial suspensions were analysed using a densitometer (DEN-1, BioSan, Warren MI, USA) and adjusted to $1 \times 10^{6}$ colony forming units $(\mathrm{CFU} / \mathrm{mL})$ by diluting with appropriate broth. The broths used were MHB, Tryptic Soy (TS, BD), Tryptic Soy supplemented with $1 \%$ glucose (TSG, ICN Biomedicals, Irvine, CA, USA), or $2 \%$ glucose (TS2G), Brain Heart Infusion (BHI, Sigma-Aldrich, St Louis, MO, USA) and Brain Heart Infusion supplemented with $1 \%$ glucose (BHIG). An aliquot of $200 \mu \mathrm{L}$ of bacterial suspension per well was dispensed into a 96-well flat bottom microplate (Nunc, Roskilde, Denmark). Negative control wells were filled with $200 \mu \mathrm{L}$ of media only. Microplates were then incubated at $37{ }^{\circ} \mathrm{C}$ for $24 \mathrm{~h}$ [Staphylococcus aureus and methicillin-resistant S. aureus (MRSA)] or $48 \mathrm{~h}$ [Enterococcus faecalis, vancomycin- resistant E. faecalis (VRE), Enterococcus faecium and E. faecium VRE].

\section{Assessment of biofilm viable cells by colony count}

Media was removed from all wells after the respective incubation times. The formed biofilm was washed once with $200 \mu \mathrm{L}$ of phosphate-buffered saline (PBS). Next, $100 \mu \mathrm{L}$ of PBS solution was added to wells containing biofilm and then biofilm cells were suspended by vigorous pipetting. The suspended biofilm was transferred to a new 96-well flat bottom microplate followed by 10 -fold dilutions prepared in PBS. Five drops of $10 \mu \mathrm{L}$ each was drop-plated on the agar respective to the broths used for biofilm production (e.g. MHA for biofilm grown in $\mathrm{MHB})$. CFU were enumerated after $24 \mathrm{~h}$

Table 1 List of bacterial strains used in this study and the corresponding antibiotic profiles

\begin{tabular}{lll}
\hline Bacterial strain & ATCC number & Antibiotic profile \\
\hline Staphylococcus aureus & 29213 & No resistance found \\
Methicillin-resistant Staphylococcus aureus & 43300 & Resistant to methicillin, oxacillin \\
Enterococcus faecium & 35667 & No resistance found \\
Vancomycin-resistant Enterococcus faecium & 70021 & Resistant to vancomycin, teichoplanin \\
Enterococcus faecalis & 29212 & No resistance found \\
Vancomycin-resistant Enterococcus faecalis & 51575 & Resistant to gentamicin, streptomycin, vancomycin
\end{tabular}


of incubation at $37{ }^{\circ} \mathrm{C}$. The experiment was performed twice with three replicates.

\section{Assessment of biofilm biomass by crystal violet staining} Biofilm biomass measurements by crystal violet (CV) staining were performed as previously described [12] with some modifications. An aliquot of $190 \mu \mathrm{L}$ of $0.01 \%$ CV (Sigma-Aldrich) aqueous solution was added to three wells of the 96-well flat bottom microplate containing biofilm, along with its respective control media (three wells), and incubated at room temperature for $30 \mathrm{~min}$. Then, CV solution was removed and wells were washed three times with $200 \mu \mathrm{L}$ of sterile water. During this wash step care was taken not to disturb the biofilm. The plate was left to dry for $30 \mathrm{~min}$ at $50{ }^{\circ} \mathrm{C}$. Next, $200 \mu \mathrm{L}$ of $96-99 \%$ ethanol was added to each well and biofilm was detached by vigorous pipetting. Absorbance measurement values at $570 \mathrm{~nm}$ were obtained using the Multiskan GO (Thermo Fisher Scientific, Vantaa, Finland). If a negative value for optical density (OD) was obtained, it was presented as zero. The experiment was performed twice with three replicates.

\section{Assessment of metabolic activity of biofilm cells by resazurin}

Biofilm production was performed using TSG broth for all bacterial strains. A stock of resazurin (Sigma-Aldrich) was prepared at $1 \mathrm{mg} / \mathrm{mL}$ in sterile PBS. The solution was filter-sterilized and stored at $4{ }^{\circ} \mathrm{C}$ in the dark. Three concentrations of resazurin solutions were investigated: $2 \mu \mathrm{g} / \mathrm{mL}, 4 \mu \mathrm{g} / \mathrm{mL}$ and $8 \mu \mathrm{g} / \mathrm{mL}$, and two incubation temperatures: $25^{\circ} \mathrm{C}$ and $37^{\circ} \mathrm{C}$. The diluted resazurin solution in PBS was prepared only on the day of the assay. For the assay, firstly biofilm was carefully washed with $200 \mu \mathrm{L}$ of PBS. Next, $100 \mu \mathrm{L}$ of diluted resazurin solution was added into each well containing biofilm, along with its respective negative controls (un-inoculated broth, three wells). Microplates were placed in the dark and incubated at $25{ }^{\circ} \mathrm{C}$ or $37{ }^{\circ} \mathrm{C}$ for $20 \mathrm{~min}$. A multimode microplate reader (Varioskan LUX, Thermo Fisher Scientific) was used to measure the relative fluorescence units (RFU) ( $\lambda_{\mathrm{Ex}} 530 \mathrm{~nm}$ and $\lambda_{\mathrm{Em}} 590 \mathrm{~nm}$ ) after incubation. Readings were repeated at 20-min intervals for up to $80 \mathrm{~min}$. The experiment was performed twice with three replicates. The optimal conditions were chosen based on the analysis of quality parameters $\left(Z^{\prime}>0.50\right)$ defined in the assays (see Additional file 1).

\section{Determination of MBIC and MBEC}

Ciprofloxacin hydrochloride (ICN Biomedicals) and linezolid (Sigma-Aldrich) stock solutions were prepared in sterile water to a concentration of $1.6 \mathrm{mg} / \mathrm{mL}$ (MBIC assays) and $32 \mathrm{mg} / \mathrm{mL}$ and $16 \mathrm{mg} / \mathrm{mL}$ for ciprofloxacin and linezolid, respectively (MBEC assays). MBIC and
MBEC assays were performed by the broth microdilution method in 96-well flat bottom microplate format adapted from the Clinical \& Laboratory Standards Institute (CLSI) guidelines [9, 13].

Briefly, bacterial suspension was diluted with TSG broth to obtain an inoculum of $1 \times 10^{6} \mathrm{CFU} / \mathrm{mL}$. Equal volumes of bacterial suspension and antibiotic solution were diluted into TSG broth, mixed together in the plate and incubated for $24 \mathrm{~h}$ at $37{ }^{\circ} \mathrm{C}$. Known minimal inhibitory concentrations (MIC) of reference antibiotics were used as positive controls (see Table 2 for details). Ciprofloxacin final concentrations tested ranged from $0.031 \mu \mathrm{g} / \mathrm{mL}$ to $8 \mu \mathrm{g} / \mathrm{mL}$ for the MBIC assays and from $0.625 \mu \mathrm{g} / \mathrm{mL}$ to $160 \mu \mathrm{g} / \mathrm{mL}$ for the MBEC assays. Linezolid final concentrations tested ranged from $0.031 \mu \mathrm{g} /$ $\mathrm{mL}$ to $8 \mu \mathrm{g} / \mathrm{mL}$ for the MBIC assays and from $0.313 \mu \mathrm{g} /$ $\mathrm{mL}$ to $80 \mu \mathrm{g} / \mathrm{mL}$ for the MBEC assays. After incubation, MBIC was defined by performing the optimized resazurin assay (i.e. Staphylococci biofilms were assayed using $4 \mu \mathrm{g} / \mathrm{mL}$ of resazurin solution with incubation at $25{ }^{\circ} \mathrm{C}$ for $20 \mathrm{~min}$, and Enterococci biofilms were assayed using $8 \mu \mathrm{g} / \mathrm{mL}$ of resazurin solution with incubation at $25{ }^{\circ} \mathrm{C}$ for $40 \mathrm{~min}$ ). CFUs were also determined after resazurin-based assay completion, in order to corroborate the results. Biofilm cells were suspended by vigorous pipetting and detached from wells. Cells were quantified by the drop-plate as described above. The MBEC was carried out in a similar manner to the MBIC, however, the Staphylococci and Enterococci biofilms were initially grown for $24 \mathrm{~h}$ and $48 \mathrm{~h}$, respectively, at $37^{\circ} \mathrm{C}$ and then treated with antibiotics for $24 \mathrm{~h}$ at $37^{\circ} \mathrm{C}$. All experiments were performed twice with three replicates.

\section{Data analysis}

The data obtained from the different media tested for biofilm growth were evaluated by Analysis of Variance (ANOVA) and then Tukey's test using SPSS version 25 software (IBM). $P$ values of less than 0.05 were regarded as significant.

The resazurin optimization assays were assessed by assay quality parameters typically employed in the development of new screening methods, i.e. $\mathrm{Z}^{\prime}, \mathrm{S} / \mathrm{B}$ and SW [14]. These parameters were also used for assessing the quality of the data obtained during the determinations of MBIC and MBEC. The Z' is reflective of both the assay signal dynamic range and the data variation associated with single measurements. The following equations were used: $\mathrm{Z}^{\prime}=1-[(3 \mathrm{SDs}+3 \mathrm{SDb}) /|\mathrm{Xs}-\mathrm{Xb}|], \mathrm{S} / \mathrm{B}=\mathrm{Xs} / \mathrm{Xb}$ and $\mathrm{SW}=[\mathrm{Xs}-\mathrm{Xb}-3(\mathrm{SDs}+\mathrm{SDb})] / \mathrm{SDs}$, where $\mathrm{Xs}$ represents the average of the signal obtained from control samples exhibiting maximum signal and SDs the related standard deviation, and $\mathrm{Xb}$ and $\mathrm{SDb}$ represent the average and standard deviation of the signal obtained from control media wells. The threshold 
Table 2 Minimal biofilm inhibitory and eradication concentrations (MBIC and MBEC) determined by resazurin and cell counting methods

\begin{tabular}{|c|c|c|c|c|c|c|}
\hline \multirow[t]{3}{*}{ Bacterial strain } & \multirow[t]{3}{*}{ Antibiotic } & \multirow[t]{3}{*}{$\mathrm{MIC}^{\mathrm{a}}(\mu \mathrm{g} / \mathrm{mL})$} & \multicolumn{2}{|l|}{$\mathrm{MBIC}(\mu \mathrm{g} / \mathrm{mL})$} & \multicolumn{2}{|l|}{$\operatorname{MBEC}(\mu \mathrm{g} / \mathrm{mL})$} \\
\hline & & & Resazurin & $\mathrm{CFU} / \mathrm{mL}^{\mathrm{b}}$ & Resazurin & $\mathrm{CFU} / \mathrm{mL}^{\mathrm{b}}$ \\
\hline & & & (decrease in RFU) & (growth inhibition) & (decrease in RFU) & $\left(\log _{10}\right.$ reduction \\
\hline Staphylococcus aureus ATCC 29213 & Ciprofloxacin & 0.5 & $1(99 \%)$ & $1(100 \%)$ & $>160(18 \%)$ & $>160(1.2)$ \\
\hline Staphylococcus aureus MRSA ATCC 43300 & Ciprofloxacin & 0.5 & $1(99 \%)$ & $1(100 \%)$ & $>160(30 \%)$ & $>160(1.7)$ \\
\hline Enterococcus faecalis ATCC 29212 & Ciprofloxacin & 1 & $1(90 \%)$ & $1(100 \%)$ & $>160(35 \%)$ & $>160(4.0)$ \\
\hline Enterococcus faecalis VRE ATCC 51575 & Ciprofloxacin & 0.5 & $1(99 \%)$ & $1(100 \%)$ & $>160(0 \%)$ & $>160(3.3)$ \\
\hline Enterococcus faecium ATCC 35667 & Linezolid & 4 & $2(96 \%)$ & $2(100 \%)$ & $>80(26 \%)$ & $>80(1.5)$ \\
\hline Enterococcus faecium VRE ATCC 70021 & Linezolid & 2 & $2(99 \%)$ & $2(97 \%)$ & $>80(26 \%)$ & $>80(1.8)$ \\
\hline
\end{tabular}

Mean of quality parameters of MBIC and MBEC assays were: $Z^{\prime}=0.83 ; S / B=14.83, S W=36.40$ and $Z^{\prime}=0.77 ; S / B=21.19$ and $S W=17.19$, respectively

a:Minimal inhibitory concentration previously determined by our group

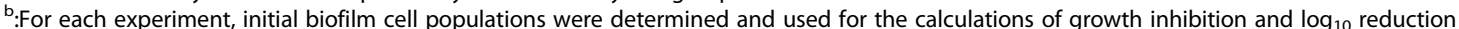

value for $\mathrm{Z}^{\prime}$ is 0.5 , indicating an excellent performance for the assay [11].

MBIC values were determined as the lowest concentration of antibiotic that displayed biofilm inhibition of $>90 \%$ based on RFU and CFU determinations. From MBEC experiments, where an MBEC value could not be determined, the percentage of decrease compared to untreated samples was calculated.

\section{Results}

\section{Assessment of biofilm biomass and cell numbers}

In this study, biofilm production of six bacterial strains (Table 1) on six different media: MHB, TS, TSG, TS2G, BHI, BHIG, after $24 \mathrm{~h}$ and $48 \mathrm{~h}$ incubation for Staphylococci and Enterococci, respectively, was evaluated. Two methods frequently used for biofilm studies were applied to assess biofilm production: $\mathrm{CV}$ and determination of CFUs.

Figure 1 shows the average results for all conditions tested. Biofilm mass, measured by the absorbance of CV at $570 \mathrm{~nm}$ was relatively low for most Enterococcus spp. tested in comparison to Staphylococcus spp., with values ranging from 0.109 to 1.151 , in contrast to 0.849 to 1.984, respectively. Both E. faecium strains had the lowest biofilm mass in MHB compared with other tested strains, with an average of 0.149 for E. faecium ATCC 35667 (Fig. 1c) and 0.109 for vancomycin resistant $E$. faecium (VRE) ATCC 700221 (Fig. 1d). It was observed that supplementing TS broth with glucose increased the biofilm production of $S$. aureus and E. faecium ATCC 35667 strains (Fig. 1a-c), although a significant difference was only observed for the methicillin-resistant $S$. aureus (MRSA) strain $(P<0.05)$ (Fig. 1b). No significant difference was observed between 1 and $2 \%$ glucose supplementation $(P>0.05)$, except for $E$. faecalis ATCC 29212 (Fig. 1e). Supplementation of BHI with glucose did not cause any significant difference $(P>0.05)$ for any of the strains tested (Fig. 1).
Average viable cell counts ranged between 7.5 and 9.4 $\log _{10} \mathrm{CFU} / \mathrm{mL}$. In general, no differences were observed in the number of viable cells and the different media used for biofilm production. The lowest CFU was observed when MRSA biofilm was grown in TSG medium, although it produced the highest biofilm mass according to the CV assay (Fig. 1b). This suggests that the increased biofilm mass observed is probably due to higher production and/or aggregation of extracellular substances in the biofilm matrix, and not to a direct increase in cell numbers.

\section{Assessment of metabolic activity of biofilm cells by resazurin}

Studies have shown that resazurin viability assay is a good alternative for quantification of biofilms grown in microplates $[9,15]$. Evaluation of assay's performance and the selection of optimal assay conditions were based on the use of typical statistical quality parameters, as described by Zhang et al. [16] and Inglese et al. [11]. Overall, the RFU, which are defined as the arbitrary units in which fluorescence intensity is reported, were higher when using resazurin solution at $8 \mu \mathrm{g} / \mathrm{mL}$ and when plates were incubated at $37{ }^{\circ} \mathrm{C}$ (Fig. 2), except for $E$. faecalis VRE ATCC 51575 (Fig. 2e). For both strains of $E$. faecalis, RFU values were still increasing at the maximum incubation time of this study (i.e. $80 \mathrm{~min}$ ) (Fig. 2c and d). For the other strains, a steady or even lower RFU values were observed at the end of the assays (Fig. 2).

Examination of the results for quality parameters (Additional file 1) revealed that most of the combinations of conditions selected for the different resazurin assays yielded an excellent $Z^{\prime}$ value (i.e. $\geq 0.5$ ), with the exception of $S$. aureus ATCC 29213. For this strain, higher variability was observed between replicates. Similar results were obtained in previous experiments when testing different media for biofilm production (Fig. 1a). 

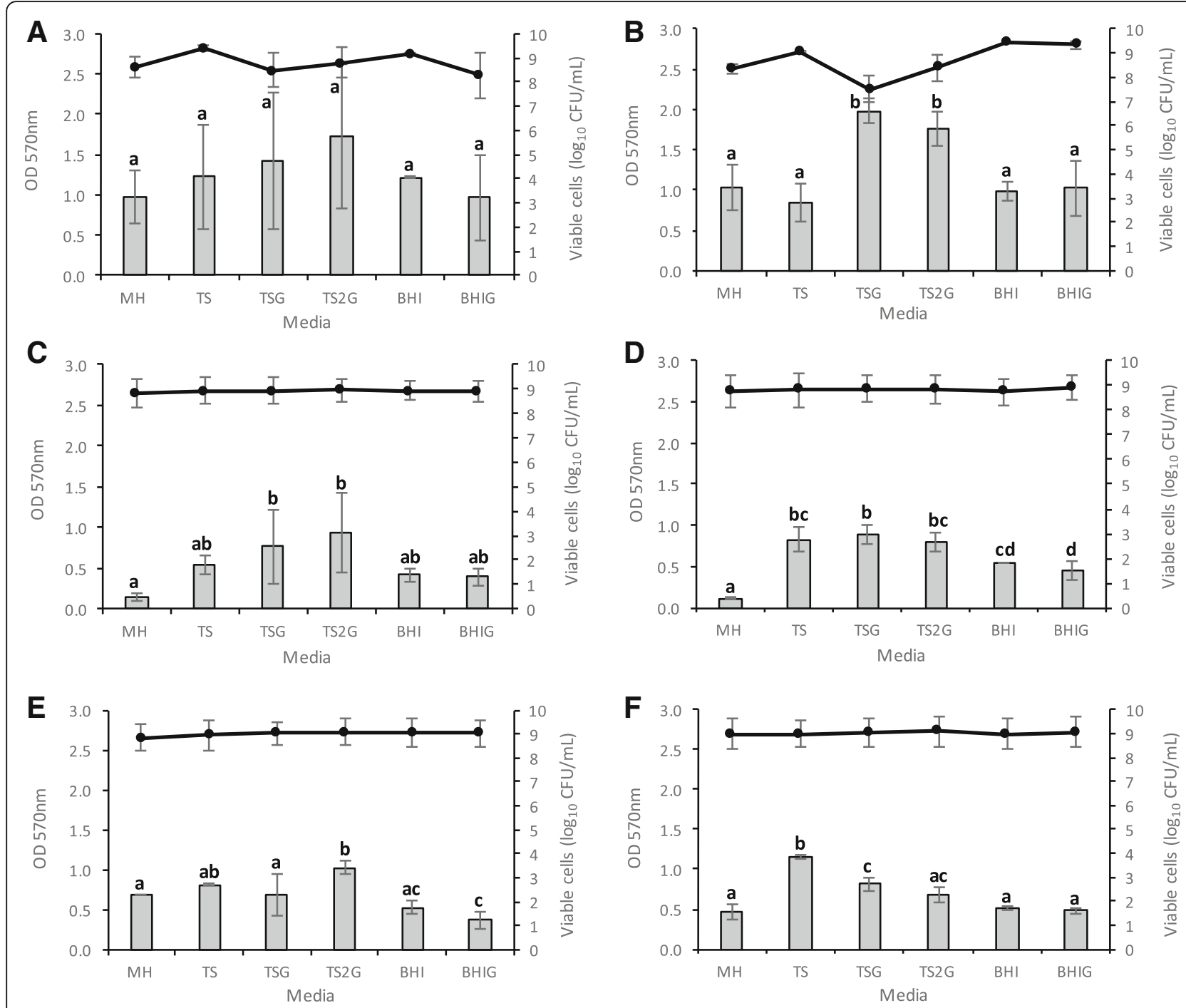

Fig. 1 Assessment of biofilm biomass by crystal violet staining and cell enumeration by colony count. Biofilm production analysis through crystal violet staining (OD $570 \mathrm{~nm}$, bars) and cell enumeration ( $\log _{10} \mathrm{CFU} / \mathrm{mL}$, lines) of six bacterial strains: (a) Staphylococcus aureus ATCC 29213, (b) Staphylococcus aureus MRSA ATCC 43300, (c) Enterococcus faecium ATCC 35667, (d) Enterococcus faecium VRE ATCC 700221, (e) Enterococcus faecalis ATCC 29212 and (f) Enterococcus faecalis VRE ATCC 51575, incubated in six different media: Mueller Hinton (MH), Tryptic Soy (TS), Tryptic Soy supplemented with 1\% glucose (TSG), Tryptic Soy supplemented with 2\% glucose (TS2G), Brain Heart Infusion (BHI) and Brain Heart Infusion supplemented with $1 \%$ glucose (BHIG). Error bars represent standard deviation of two independent experiments in triplicate. Lowercase letters indicate significant differences amongst media used for biofilm production. Similar letters denote no significant difference $(P>0.05)$

The conditions for the resazurin assay selected for further experiments were set as follows: $4 \mu \mathrm{g} / \mathrm{mL}$ and $8 \mu \mathrm{g} / \mathrm{mL}$, with incubation at $25{ }^{\circ} \mathrm{C}$ for $20 \mathrm{~min}$ and $40 \mathrm{~min}$ for Staphylococci and Enterococci, respectively. These were selected based on the quality parameter Z', as well on previous published data (to facilitate further comparison with other studies [17-19]), when Z' was satisfactory in more than one combination of parameters.

\section{MBIC and MBEC determination}

Using the previously optimized assays, we assessed the MBIC and MBEC of ciprofloxacin and linezolid for the six bacterial strains. Biofilms were grown in TSG media and resazurin assays were conducted as follows: $4 \mu \mathrm{g} / \mathrm{mL}$ of resazurin with an incubation of $20 \mathrm{~min}$ at $25^{\circ} \mathrm{C}$ for Staphylococci biofilms and $8 \mu \mathrm{g} / \mathrm{mL}$ of resazurin with an incubation of $40 \mathrm{~min}$ at $25^{\circ} \mathrm{C}$ for Enterococci biofilms, based on findings obtained during the assessment of metabolic activity of biofilm cells (Fig. 2).

A limitation of using the resazurin-based assay is the low linear range and detection limit of viable cells (i.e. $10^{6}$ cells per biofilm, [15]). Thus, conditions leading to higher RFU values were chosen, combined with the quality parameters' assessment, for an acceptable assay. 


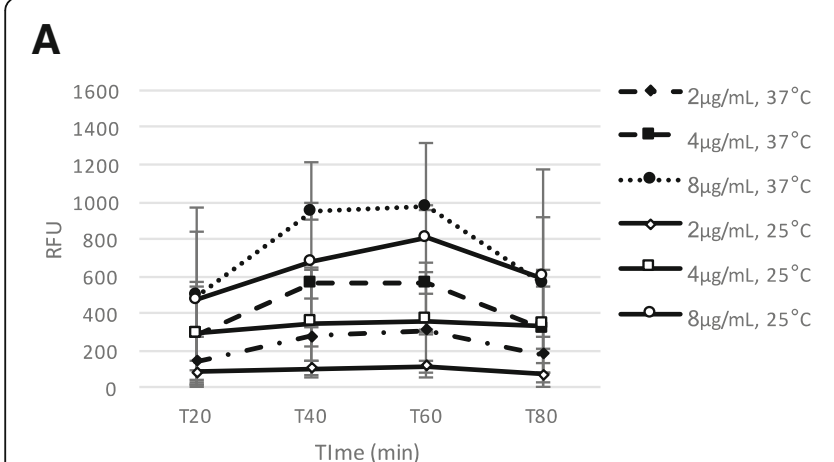

B

C

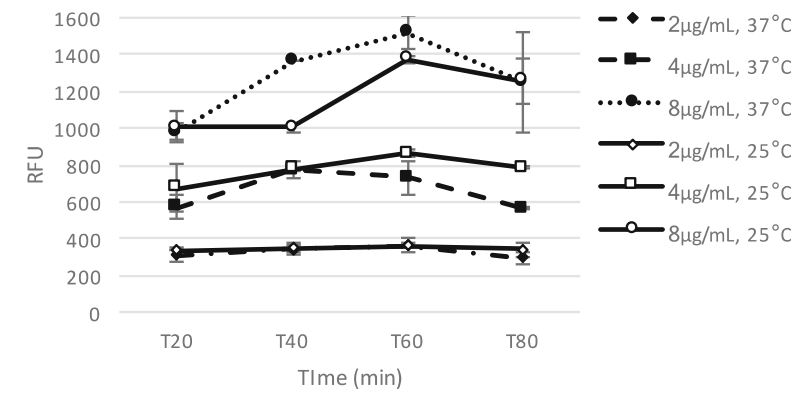

D
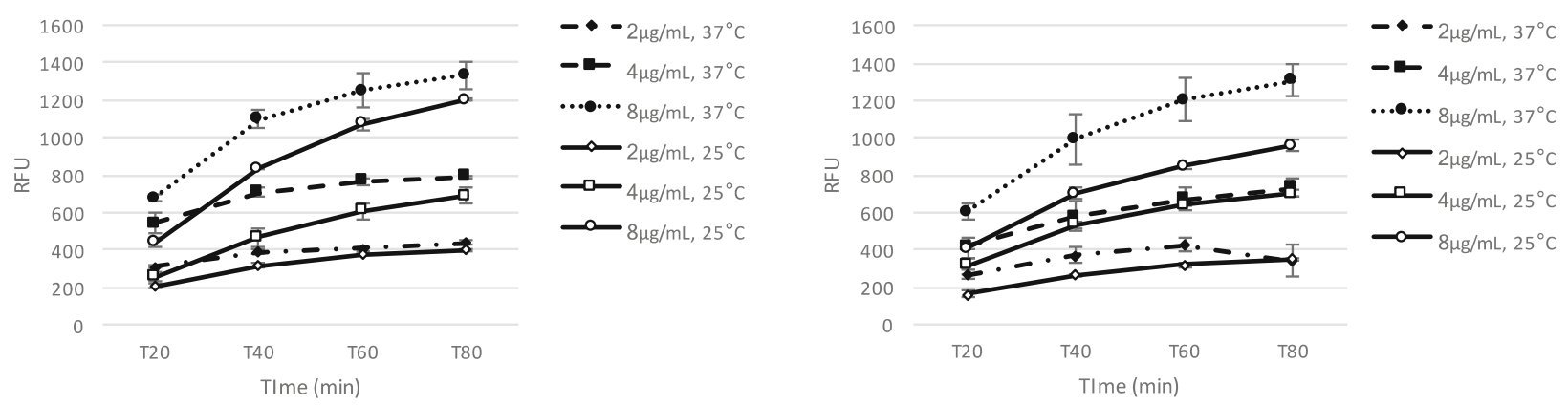

E

$\mathbf{F}$
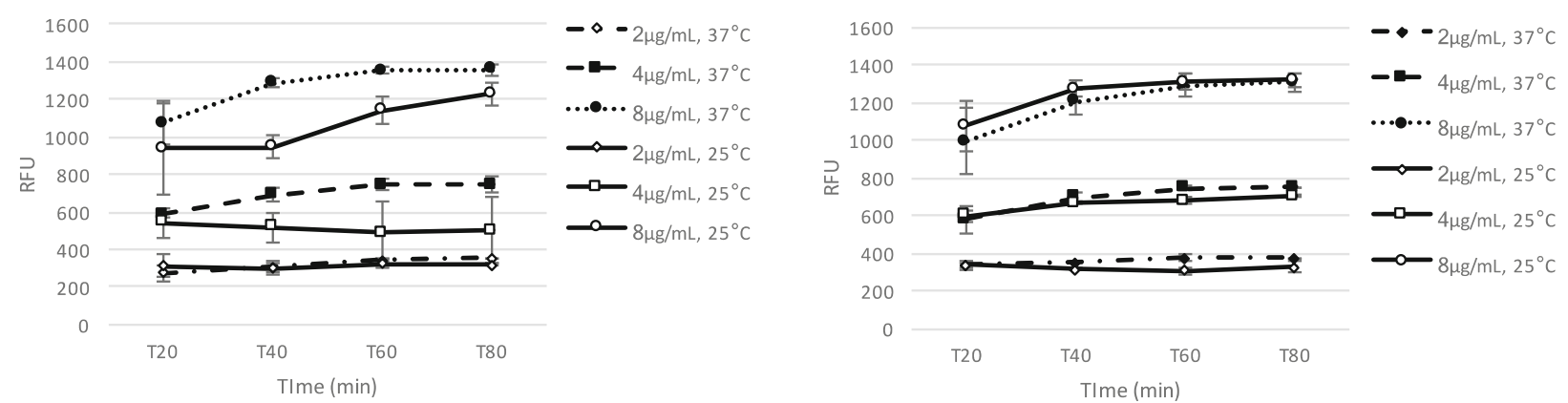

Fig. 2 Assessment of metabolic activity of biofilm cells by resazurin. Quantification of biofilm production of six bacterial strains, using three concentrations of resazurin solution (2, 4 and 8 rg/mL): (a) Staphylococcus aureus ATCC 29213, (b) Staphylococcus aureus MRSA ATCC 43300, (c) Enterococcus faecium ATCC 35667, (d) Enterococcus faecium VRE ATCC 700221, (e) Enterococcus faecalis ATCC 29212, (F) Enterococcus faecalis VRE ATCC 51575, incubated at $25^{\circ} \mathrm{C}$ and $37^{\circ} \mathrm{C}$. Relative fluorescence measurements were taken at 20, 40, 60 and 80 min

In order to validate the results obtained with the resazurin-based assay for MBIC and MBEC determinations, CFU counts were also determined using the same samples.

Two strains presented a MBIC value similar to their respective MIC, while $S$. aureus strains and E. faecalis VRE ATCC 51575 had a ciprofloxacin MBIC higher than the MIC by 2-fold. E. faecium ATCC 35667, showed a 2 -fold lower linezolid MBIC than its respective MIC. Although differences were observed for MIC and MBIC of some bacterial strains, these are not significant. MBIC values were similar by two methods employed: resazurin and CFU counts. The quality of the resazurin-based assay for MBIC determination was acceptable, with an average $Z^{\prime}$ of 0.83 and S/B and SW higher than 2-fold (Table 2) [11].

The MBEC was defined as the minimal concentration of antibiotic required to reduce biofilm cell numbers below detection limit of the assays used (i.e. $10^{6} \mathrm{CFU} /$ $\mathrm{mL}$ for resazurin-based assay and $10^{2} \mathrm{CFU} / \mathrm{mL}$ for cell counting method). We also consider that a successful biofilm eradication should be complete, thus there is no bacterial survivors to multiply and restore colonization. Based on these assumptions MBEC was not achieved 
with the two tested antibiotics even at the highest concentrations.

Evaluation of the percentage of decrease obtained in the MBEC assays showed that the results varied depending on the assay used, i.e. for the resazurin assay RFU values showed a lower decrease in comparison to bacterial quantification method (Table 2). This finding corroborates what has been shown by Peeters et al. [15], elucidating the limitation of the use of the resazurin assays for some applications on biofilm research.

Overall a 3 to $4 \log _{10}$ CFU reduction was achieved by treating biofilm cells of E. faecalis ATCC 35667 and E. faecalis VRE ATCC 51575 with $160 \mu \mathrm{g} / \mathrm{mL}$ ciprofloxacin, respectively. This reduction corresponded to a decrease in RFU of about $35 \%$ and $16 \%$, while for other bacterial biofilms tested, at maximum antibiotic concentrations, only $1.7 \log _{10}$ CFU reduction or even less was observed (Table 2).

\section{Discussion}

Stepanovic et al. [9] reviewed several studies on testing different conditions for $S$. aureus biofilms. Concordant with our results, TS broth supplemented with $1 \%$ glucose had the best performance, with an incubation time of $24 \mathrm{~h}[12,20]$. Some strains of Staphylococci have been shown to produce more biofilm in BHI [20, 21].

Enterococci biofilm production also differs between different species depending on the media used in the assays. Baldassari et al. [22] and Pilai et al. [23] reported that TS broth supplemented with $1 \%$ glucose increased biofilm production of E. faecalis, which is similar to our findings. Mohamed et al. [6] compiled some studies on biofilm production by Enterococci that suggested that $E$. faecalis produces biofilm more often and stronger than E. faecium, independent of the media used in the assays. TS broth supplemented with $0.5 \%$ to $1 \%$ glucose seems to be a common media used elsewhere for Enterococcus spp. biofilm [24-26].

Composition of the medium is probably the most important factor influencing the ability of bacteria to produce biofilm under in vitro conditions. Accordingly, presence of carbohydrate plays an important role in biofilm production amongst Gram-positive bacteria.

Although a clear recommendation for the use of a single medium appropriate for all Staphylococci and Enterococci when testing biofilms is difficult, our results revealed TS broth supplemented with $1 \%$ glucose to be the medium of choice for the clinical laboratory reference strains tested in our study.

Optimal incubation time also differed between bacterial species. Enterococcus spp. had a poor biofilm production after a $24 \mathrm{~h}$ incubation at $37{ }^{\circ} \mathrm{C}$ (data not shown); the incubation time was therefore extended to $48 \mathrm{~h}$. This phenomenon has been observed elsewhere [27], mostly for VRE strains [25].

The development of new anti-biofilm agents is hindered by the lack of a reliable and accurate method for screening of activity (i.e. determination of MBIC and/or MBEC). To determine antibacterial activity, several studies have combined two staining assays for measuring the total biomass and viability of biofilms using $\mathrm{CV}$, CFU and/or resazurin [17, 28, 29-32].

Here, we opted for the resazurin assay to establish the MBIC and MBEC for selected antibiotics. This methodology has some pros and cons as described by Sandberg et al. and Peeters et al. $[15,18]$; they noted that optimal resazurin parameters should be established for every tested bacterial strain when using this method as a screening tool. The results in RFU values generated from the assay have also to be interpreted carefully since this method has a lower limit of quantification (method cannot discriminate cell numbers lower than $10^{6} \mathrm{CFU}$ per biofilm). Thus lower numbers of viable cells cannot be measured, requiring a supplemented method, such as CFU counts. Van den Driessche [33] has recently described an optimized resazurin-based quantification for some microbial biofilms lowering the detection limit of $10^{3} \mathrm{CFU}$. Nevertheless, the resazurin assay is a very easy and reproducible method, ideal for higher throughput in screening, and when used for the determination of MBIC it performs well.

The quality of the resazurin assay was evaluated based on its reproducibility and on three quality parameters: SW, S/B and Z'. To our knowledge, this is the first study to evaluate the resazurin assay for MBIC and MBEC determinations using this approach.

The difficulty in eradicating S. aureus biofilms using ciprofloxacin is consistent with earlier data using other antibacterial agents [34, 35]. The selection of ciprofloxacin for our study was based on its current use as a standard positive control for MIC determinations as recommended by CLSI [13]. For the determination of $S$. aureus MBEC, another drug should be selected as a positive control. Still the results presented in this work show the feasibility of a standardized resazurin assay for MBIC and MBEC determinations, followed by an appropriate quality assessment by using statistical parameters. Overall, MBEC requires a complementing method to accurately determine effects on biofilms $[28,36]$.

In this study, the resazurin assay was used to determine the MBIC and MBEC values. Data obtained reveal that the resazurin assay is an acceptable choice for MBIC determination. The anti-biofilm assays of selected antibiotics were performed under optimized biofilm growth conditions and detection of metabolically active cells for Gram-positive laboratory reference strains. Bridging the gap between results obtained in in vitro to 
in vivo outcomes is challenging, thus this present study only provided guidelines for screening tools that could be useful in the biofilm research field.

\section{Conclusions}

The clinical relevance of Staphylococci and Enterococci is related to their ability to form biofilms, which are complex biological structures highly tolerant to antibiotic treatment.

This study shows the importance of media selection for biofilm growth and the optimization of assays concurrent with quality parameter assessment. We have described here a useful and standardized tools for MBIC and MBEC determinations when screening and evaluating compounds with potential anti-biofilm activity. The clinical impact of the data obtained using the optimized methodology has not been evaluated in this study, thus further experiments are required to assess this aspect.

\section{Additional file}

Additional file 1: Quality parameters from resazurin optimization assays for assessing metabolic activity of biofilm cells. This table provides all the quality parameter (Z prime, signal to background and signal window) results calculated for each of the resazurin conditions tested and for the six bacterial strains used in the study. (DOCX $35 \mathrm{~kb}$ )

\section{Abbreviations}

ANOVA: Analysis of variance; $\mathrm{BHI}$ : Brain heart infusion; $\mathrm{BHIG}$ : Brain heart infusion supplemented with 1\% glucose; CFU: Colony-forming units; CLSI: Clinical \& Laboratory Standards Institute; CV: Crystal violet; E. faecalis: Enterococcus faecalis; E. faecium: Enterococcus faecium; EPS: Exopolysaccharide; MBEC: Minimal biofilm eradication concentration; MBIC: Minimal biofilm inhibitory concentration; MHA: Mueller hinton agar; MHB: Mueller hinton broth; MIC: Minimal inhibitory concentration; MRSA: Methicillin-resistant S. aureus; OD: Optical density; PBS: Phosphate-buffered saline; RFU: Relative fluorescence units; $S$. aureus: Staphylococcus aureus; S/B: Signal to background; SW: Signal window; TS: Tryptic soy; TS2G: Tryptic soy supplemented with 2\% glucose; TSG: Tryptic soy supplemented with $1 \%$ glucose; VRE: Vancomycin-resistant Enterococcus; Z: Z prime

\section{Acknowledgements}

The authors (CDC and PT) thank the Academy of Finland (Grant nos. 277001 and 304697) for financial support. SS thanks the Erasmus programme and the European University Consortium for Pharmaceutical Sciences for the grant provided during internship.

\section{Funding}

Funding was provided by the Academy of Finland (Grant nos. 277001 and 304697), the Erasmus programme and the European University Consortium for Pharmaceutical Sciences. The funding body had no role in the design of the study, in the collection, analysis or interpretation of data or in the writing of the manuscript.

\section{Availability of data and materials}

All data generated or analysed during this study are included in this article. Raw datasets are available from the corresponding author on reasonable request.

\section{Authors' contributions}

CDC: Study conception and design; data collection, analysis and interpretation; writing of the article; final approval of the article. SS: Data collection, analysis and interpretation; writing of the article; final approval of the article. PT: Critical revision of the article; final approval of the article.
Ethics approval and consent to participate

Not applicable.

\section{Consent for publication}

Not applicable.

\section{Competing interests}

The authors declare that the research was conducted in the absence of any commercial or financial relationship that could be construed as a potential conflict of interest. The authors have no competing interests.

\section{Publisher's Note}

Springer Nature remains neutral with regard to jurisdictional claims in published maps and institutional affiliations.

Received: 23 April 2018 Accepted: 17 October 2018

Published online: 03 November 2018

\section{References}

1. del Pozo JL, Patel R. The challenge of treating biofilm-associated bacterial infections. Clin Pharmacol Ther. 2007;82(2):204-9.

2. Mah TF, O'Toole GA. Mechanisms of biofilm resistance to antimicrobial agents. Trends Microbiol. 2001;9(1):34-9.

3. Donlan RM, Costerton JW. Biofilms: survival mechanisms of clinically relevant microorganisms. Clin Microbiol Rev. 2002;15(2):167-93.

4. Chu VH, Crosslin DR, Friedman JY, Reed SD, Cabell CH, Griffiths RI, Masselink LE, Kaye KS, Corey GR, Reller LB, et al. Staphylococcus aureus bacteremia in patients with prosthetic devices: costs and outcomes. Am J Med. 2005; 118(12):1416.

5. Joo HS, Otto M. Molecular basis of in vivo biofilm formation by bacterial pathogens. Chem Biol. 2012;19(12):1503-13.

6. Mohamed JA, Huang DB. Biofilm formation by enterococci. J Med Microbiol. 2007:56(Pt 12):1581-8.

7. Jett BD, Huycke MM, Gilmore MS. Virulence of enterococci. Clin Microbiol Rev. 1994:7(4):462-78

8. Extremina $\mathrm{Cl}$, Costa L, Aguiar Al, Peixe L, Fonseca AP. Optimization of processing conditions for the quantification of enterococci biofilms using microtitre-plates. J Microbiol Methods. 2011;84(2):167-73.

9. Stepanovic S, Vukovic D, Hola V, Di Bonaventura G, Djukic S, Cirkovic I, Ruzicka F. Quantification of biofilm in microtiter plates: overview of testing conditions and practical recommendations for assessment of biofilm production by staphylococci. APMIS. 2007;115(8):891-9.

10. Lebeaux D, Ghigo JM, Beloin C. Biofilm-related infections: bridging the gap between clinical management and fundamental aspects of recalcitrance toward antibiotics. Microbiol Mol Biol Rev. 2014;78(3):510-43.

11. Inglese J, Johnson RL, Simeonov A, Xia M, Zheng W, Austin CP, Auld DS High-throughput screening assays for the identification of chemical probes. Nat Chem Biol. 2007:3(8):466-79.

12. Stepanovic S, Vukovic D, Dakic I, Savic B, Svabic-Vlahovic M. A modified microtiter-plate test for quantification of staphylococcal biofilm formation. J Microbiol Methods. 2000;40(2):175-9.

13. CLSI. Methods for dilution antimicrobial susceptibility tests for Bacteria that grow aerobically, approved standard. 9th ed. CLSI document M07-A9. Wayne: Clinical and Laboratory Standards Institute; 2012.

14. Kreander K, Vuorela P, Tammela P. A rapid screening method for detecting active compounds against erythromycin-resistant bacterial strains of Finnish origin. Folia Microbiol (Praha). 2005;50(6):487-93.

15. Peeters $\mathrm{E}$, Nelis HJ, Coenye T. Comparison of multiple methods for quantification of microbial biofilms grown in microtiter plates. J Microbiol Methods. 2008;72(2):157-65.

16. Zhang JH, Chung TD, Oldenburg KR, Simple Statistical A. Parameter for use in evaluation and validation of high throughput screening assays. J Biomol Screen. 1999;4(2):67-73.

17. Skogman ME, Vuorela PM, Fallarero A. Combining biofilm matrix measurements with biomass and viability assays in susceptibility assessments of antimicrobials against Staphylococcus aureus biofilms. J Antibiot (Tokyo). 2012;65(9):453-9.

18. Sandberg ME, Schellmann D, Brunhofer G, Erker T, Busygin I, Leino R, Vuorela PM, Fallarero A. Pros and cons of using resazurin staining for quantification of viable Staphylococcus aureus biofilms in a screening assay. J Microbiol Methods. 2009;78(1):104-6. 
19. Sandberg M, Maattanen A, Peltonen J, Vuorela PM, Fallarero A. Automating a 96-well microtitre plate model for Staphylococcus aureus biofilms: an approach to screening of natural antimicrobial compounds. Int J Antimicrob Agents. 2008:32(3):233-40.

20. Knobloch JK, Horstkotte MA, Rohde H, Mack D. Evaluation of different detection methods of biofilm formation in Staphylococcus aureus. Med Microbiol Immunol. 2002;191(2):101-6.

21. Mathur T, Singhal S, Khan S, Upadhyay DJ, Fatma T, Rattan A. Detection of biofilm formation among the clinical isolates of Staphylococci: an evaluation of three different screening methods. Indian J Med Microbiol. 2006;24(1):25-9.

22. Baldassarri L, Cecchini R, Bertuccini L, Ammendolia MG, losi F, Arciola CR, Montanaro L, Di Rosa R, Gherardi G, Dicuonzo G, et al. Enterococcus spp. produces slime and survives in rat peritoneal macrophages. Med Microbiol Immunol. 2001;190(3):113-20.

23. Pillai SK, Sakoulas G, Eliopoulos GM, Moellering RC Jr, Murray BE, Inouye RT. Effects of glucose on fsr-mediated biofilm formation in Enterococcus faecalis. J Infect Dis. 2004;190(5):967-70.

24. Mohamed JA, Murray BE. Lack of correlation of gelatinase production and biofilm formation in a large collection of Enterococcus faecalis isolates. J Clin Microbiol. 2005;43(10):5405-7.

25. Ramadhan AA, Hegedus E. Biofilm formation and esp gene carriage in enterococci. J Clin Pathol. 2005:58(7):685-6.

26. Neudorfer K, Schmidt-Malan SM, Patel R. Dalbavancin is active in vitro against biofilms formed by dalbavancin-susceptible enterococci. Diagn Microbiol Infect Dis. 2018;90(1):58-63.

27. Di Rosa R, Creti R, Venditti M, D'Amelio R, Arciola CR, Montanaro L, Baldassarri L. Relationship between biofilm formation, the enterococcal surface protein (Esp) and gelatinase in clinical isolates of Enterococcus faecalis and Enterococcus faecium. FEMS Microbiol Lett. 2006;256(1):145-50.

28. Reiter KC, Villa B, Paim TG, de Oliveira CF, d'Azevedo PA. Inhibition of biofilm maturation by linezolid in meticillin-resistant Staphylococcus epidermidis clinical isolates: comparison with other drugs. J Med Microbiol. 2013;62(Pt 3):394-9.

29. Sandoe JA, Wysome J, West AP, Heritage J, Wilcox MH. Measurement of ampicillin, vancomycin, linezolid and gentamicin activity against enterococcal biofilms. J Antimicrob Chemother. 2006;57(4):767-70.

30. Campana R, Casettari L, Fagioli L, Cespi M, Bonacucina G, Baffone W. Activity of essential oil-based microemulsions against Staphylococcus aureus biofilms developed on stainless steel surface in different culture media and growth conditions. Int J Food Microbiol. 2017;241:132-40.

31. Mariscal A, Lopez-Gigosos RM, Carnero-Varo M, Fernandez-Crehuet J. Fluorescent assay based on resazurin for detection of activity of disinfectants against bacterial biofilm. Appl Microbiol Biotechnol. 2009;82(4):773-83.

32. Costa GA, Rossatto FCP, Medeiros AW, Correa APF, Brandelli A, Frazzon APG, Motta ASD. Evaluation antibacterial and antibiofilm activity of the antimicrobial peptide P34 against Staphylococcus aureus and Enterococcus faecalis. An Acad Bras Cienc. 2018;90(1):73-84.

33. Van den Driessche F, Rigole P, Brackman G, Coenye T. Optimization of resazurin-based viability staining for quantification of microbial biofilms. J Microbiol Methods. 2014;98:31-4.

34. Wiederhold NP, Coyle EA, Raad II, Prince RA, Lewis RE. Antibacterial activity of linezolid and vancomycin in an in vitro pharmacodynamic model of grampositive catheter-related bacteraemia. J Antimicrob Chemother. 2005;55(5):792-5.

35. Raad I, Hanna H, Jiang Y, Dvorak T, Reitzel R, Chaiban G, Sherertz R, Hachem R. Comparative activities of daptomycin, linezolid, and tigecycline against catheter-related methicillin-resistant Staphylococcus bacteremic isolates embedded in biofilm. Antimicrob Agents Chemother. 2007:51(5):1656-60.

36. Macia MD, Rojo-Molinero E, Oliver A. Antimicrobial susceptibility testing in biofilm-growing bacteria. Clin Microbiol Infect. 2014;20(10):981-90.

Ready to submit your research? Choose BMC and benefit from:

- fast, convenient online submission

- thorough peer review by experienced researchers in your field

- rapid publication on acceptance

- support for research data, including large and complex data types

- gold Open Access which fosters wider collaboration and increased citations

- maximum visibility for your research: over $100 \mathrm{M}$ website views per year

At BMC, research is always in progress.

Learn more biomedcentral.com/submissions 